University of New Hampshire

University of New Hampshire Scholars' Repository

$9-2000$

\title{
Interactive 3-D Visualization: A tool for seafloor navigation, exploration, and engineering
}

\author{
Larry A. Mayer \\ University of New Hampshire, larry.mayer@unh.edu \\ Mark Paton \\ Interactive Visualization Systems \\ Lindsay Gee \\ IVS 3D Inc \\ James V. Gardner \\ University of New Hampshire, Durham, jim.gardner@unh.edu \\ Colin Ware \\ University of New Hampshire, Durham, colin.ware@unh.edu
}

Follow this and additional works at: https://scholars.unh.edu/ccom

Part of the Oceanography and Atmospheric Sciences and Meteorology Commons

\section{Recommended Citation}

Mayer, Larry A.; Paton, Mark; Gee, Lindsay; Gardner, James V.; and Ware, Colin, "Interactive 3-D Visualization: A tool for seafloor navigation, exploration, and engineering" (2000). IEEE Oceans. 208.

https://scholars.unh.edu/ccom/208

This Conference Proceeding is brought to you for free and open access by the Center for Coastal and Ocean Mapping at University of New Hampshire Scholars' Repository. It has been accepted for inclusion in Center for Coastal and Ocean Mapping by an authorized administrator of University of New Hampshire Scholars' Repository. For more information, please contact Scholarly.Communication@unh.edu. 


\title{
Interactive 3-D Visualization: A tool for seafloor navigation, exploration and engineering 1
}

\author{
Larry A. Mayer ${ }^{2}$ \\ Mark Paton and Lindsay $\mathrm{Gee}^{3}$ \\ James V. Gardner ${ }^{A}$ \\ Colin Ware ${ }^{2}$ \\ ${ }^{2}$ Center for Coastal and Ocean Mapping, University of New Hampshire, Durham, N.H. 03824 \\ ${ }^{3}$ Interactive Visualization Systems, Fredericton, N.B. Canada E3B5A3 \\ ${ }^{4}$ Western Coastal and Marine Geology, U.S.G.S., Menlo Park, CA 94025-3591
}

\begin{abstract}
Recent years have seen remarkable advances in sonar technology, positioning capabilities, and computer processing power that have revolutionized the way we image the seafloor. The massive amounts of data produced by these systems present many challenges but also offer tremendous opportunities in terms of visualization and analysis. We have developed a suite of interactive 3-D visualization and exploration tools specifically designed to facilitate the interpretation and analysis of very large (10's to 100's of megabytes), complex, multi-component spatial data sets. If properly georeferenced and treated, these complex data sets can be presented in a natural and intuitive manner that allows the integration of multiple components each at their inherent level of resolution and without compromising the quantitative nature of the data. Artificial sun-illumination, shading, and 3-D rendering can be used with digital bathymetric data (DTM's) to form natural looking and easily interpretable, yet quantitative, landscapes. Color can be used to represent depth or other parameters (like backscatter or sediment properties) which can be draped over the DTM, or high resolution imagery can be texture mapped on bathymetric data. When combined with interactive analytical tools, this environment has facilitated the use of multibeam sonar and other data sets in a range of geologic, environmental, fisheries, and engineering applications.
\end{abstract}

\section{INTRODUCTION}

Until the Second World War almost all bathymetric or hydrographic soundings were made by lead line. These measurements were simple to make but tremendously timeconsuming and, in deeper waters, could be quite inaccurate. With the advances in echo sounding during the war, bathymetric or hydrographic sounders became generally available resulting in the ability to make much more rapid measurements of depth (Table 1). The fundamental limitation of these systems was their large acoustic footprint (a function of their broad beam-width) and lack of any angular resolution within this footprint. Each depth measurement could only be assumed to come from directly below the vessel but with an uncertainty that was on the order of the water depth.

Positioning systems at the time provided positional information that was also on order of acoustic footprint size so there was a nice match in uncertainties associated with the location of a sounding. Surveys with these systems were typically run so as to produce relatively dense data along track but with widely spaced tracks. Narrow beam echo sounders were developed that resolved the angular ambiguity problem but were very limited in their ability to cover the seafloor. At best, these systems produced relatively sparse sounding data that was represented on a chart as selected soundings or interpolated to produce contours.

With the development of multibeam sonars and other high-resolution swath mapping systems (interferometric sonars, high-resolution sidescan sonars, laser airborne depth sounders, and laser line scanners) in concert with advances in positioning systems and computer processing power, our ability to map the seafloor has fundamentally changed. We now have the ability to obtain near complete coverage of relatively large areas of the seabed with unprecedented detail. This new perspective of seafloor morphology has the potential to revolutionize our understanding of seafloor processes in much the same way that airborne and satellitederived imagery has revolutionized our understanding of terrestrial processes. Such a revolution does not come without a price, however, and, in this case the price is one of data density. The massive amounts of data collected by these new systems present tremendous challenges in terms of interaction, integration and interpretation. A particularly challenging issue is the fusion of multiple data sets from different sensors in a manner that preserves the inherent resolution of each data set yet allows them to be seamlessly integrated.

If properly handled, however, the inherent density of the data available from these systems also presents tremendous opportunities. In this paper we will present an interactive 3$D$ visualization approach developed to take full advantage of this data density and, in doing so, to allow the user to interact with, explore, and analyze, complex. multidimensional data in a natural and intuitive manner. 


\section{THE CONVERGENCE OF TECHNOLOGIES}

When first introduced into the public sector in the early 1970 's, multibeam sonars were deep-water $(12 \mathrm{kHz})$ systems with a small number of beams (16) and a limited overall swath width (90 degrees) [1]. Since that time we have seen rapid advancements in the number of beams available (now typically more than 100), the beamwidths achievable (typically on the order of 1 or 2 degrees), and the angular sector covered (typically greater than 120 degrees - though always limited by attenuation in deeper water). We can thus ensonify very large areas of the seafloor while maintaining high lateral (typically better than $2-5 \%$ of water depth -beamwidth dependent) and vertical (typically better than $.05 \%$ of water depth -- pulse-length dependent) resolution at speeds better than 9 knots (if hull mounted).

Within the last 10 years many manufacturers have also added the ability to simultaneously collect backscatter data (either full backscatter time-series or average reflectivity over the beam footprint) resulting in sidescan sonar-like imagery that can be co-registered directly with the bathymetry.

Deep water systems have relatively low duty cycles (the systems must wait until they receive the returns from the outermost beam before the next cycle begins) and thus do not pose a serious challenge in terms of data rates. Shallow water systems, however, have very high ping rates $(10$ s per second) and can thus generate hundreds of megabytes of data per hour (Table 1). Table 1 is based on $100 \mathrm{~m}$ water depth; in $5 \mathrm{~m}$ of water, the EM3000 would collect about 17 million soundings and about 450 Mbytes of data per hour!

Table 1

Number of Soundings per hour collected in $100 \mathrm{~m}$ of water for leadline, single beam echo sounder and 3 generations of multibeam sounders. EM1000 and 3000 have full-time series backscatter and thus the increase in data density.

\begin{tabular}{|c|c|c|}
\hline Method & $\underline{\text { Soundings/hr }}$ & $\underline{M b / h r}$ \\
\hline Lead line & 10 & .00008 \\
\hline Echo sounder & 21,600 & .1728 \\
\hline EM-100 & 292,000 & 2.1 \\
\hline EM-1000 & 324,000 & $27.9(\mathrm{ss})$ \\
\hline EM-3000 & $\underline{1,500,000}$ & $\underline{79.8(\mathrm{ss})}$ \\
\hline
\end{tabular}

With the improvements in both vertical and lateral resolution of the sounders has come a concomitant and necessary improvement in the ability to measure both the position and the motion of the survey vessel (and thus our ability to determine the location of the sounding). With the latest Real-Time Kinematic (RTK) GPS systems, the position of the antenna on a vessel can be determined to 5 $\mathrm{cm}$ in $\mathrm{x}, \mathrm{y}$ and $\mathrm{z}$. When integrated with the latest inertial motion sensors, vessel attitude can be determined to .01 degree, heading to .02 degrees, and speed to $.01 \mathrm{~m} / \mathrm{sec}$ all at a $200 \mathrm{~Hz}$ update rate.
The data rates described above would have proven unmanageable without the remarkable advances that have also taken place in computer processing power. Over the past 30 years computer speed has doubled every 50 months (at least), processor costs have been cut in half every 32 months and memory costs have halved every 18 months. Additionally, we have seen the time necessary to transfer 1 Gigabyte of data drop from 75 hours with a $28.8 \mathrm{Kbaud}$ modem to about 8 seconds with a T-1000 line.

It is this convergence of rapid advances in sonar, positioning, and computing technologies that has set the scene for a new era of undersea exploration. We now describe a set of tools that take full advantage of the remarkable density of modern seafloor mapping data for a range of geologic, environmental and engineering applications.

\section{3-D DATA EXPLORATION}

To meet the challenges and take advantage of the opportunities posed by very dense data, we have developed a suite of interactive 3-D visualization and exploration tools specifically designed to facilitate the interpretation and analysis of very large (10's to 100's of megabytes), complex, multi-component spatial data sets. We contend that if properly georeferenced and treated, these complex data sets can be presented in a natural and intuitive manner that allows the simple integration of multiple components without compromise to the quantitative aspects of the data.

The software package allows the import of a variety of data types (either gridded or ungridded) from common mapping packages (GRASS, GMT/NetCDF, ESRI, ISIS, etc.) as well ASCII data and/or a range of image file types. Simple tools allow the assignment pre-existing color maps or the design of specialized ones. Once a color map is assigned to the data set, a lighting model is chosen including artificial sun-illumination, shading and true shadow calculations. The scene is then rendered to form a 3-D image that is natural looking and easily interpretable, yet fully georeferenced and quantitative.

To explore the increase in information provided by the 3-D environment we take a multibeam sonar data set collected in San Francisco Bay and display it only as $10 \mathrm{~m}$ contours (Fig.1). Any finer contour interval would result in the loss of all information in the southwest corner of the survey where the topography is steep. We then look at the same data set displayed as color-coded, shaded depth in the interactive 3-D environment (Fig.2). The differences are remarkable. While the contour data (Fig. 1) is mostly blank space, the 3-D rendering shows a range of details that could never be discerned in contoured data including system artifacts and bedforms ranging from $2 \mathrm{~m}$ to $10 \mathrm{~cm}$ in amplitude (Figs. 2 and 3). 


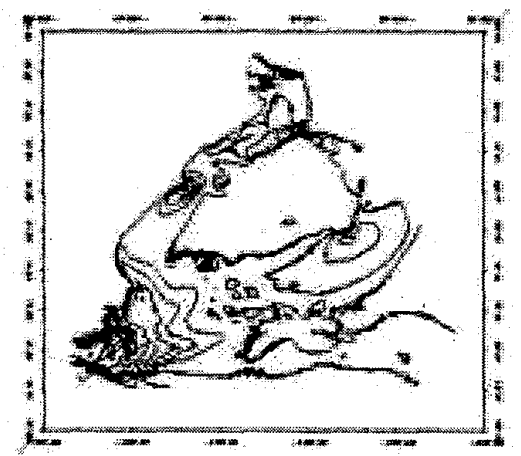

Fig. 1. $95 \mathrm{kHz}$ multibeam data from San Francisco Bay. Data set has been contoured at $10 \mathrm{~m}$ interval. USGS data.

It is important to note that while such displays offer a natural and detailed view of seafloor morphology, they are also fully quantitative. All points are georeferenced and can be interrogated in the 3-D scene for position, depth and any other attribute; measurements can be made and data sets profiled for interactive analyses (Fig. 3).

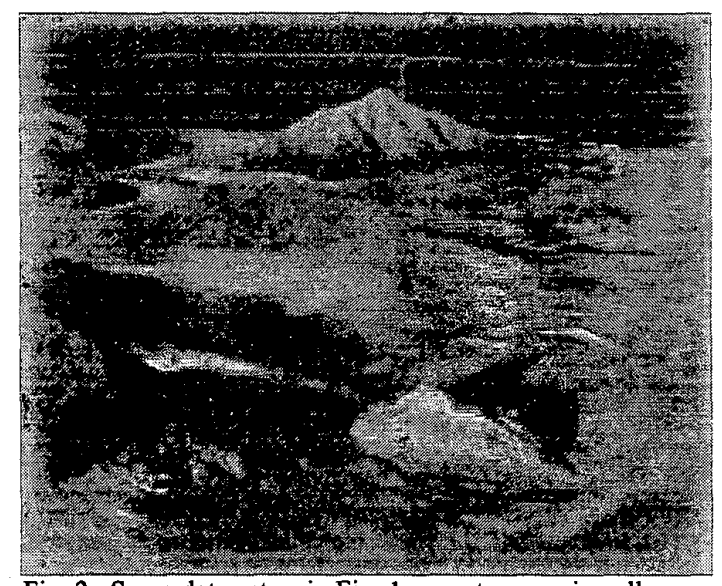

Fig. 2. Same data set as in Fig. 1 except now using all All data to create DTM and displayed in interactive 3-D environment. Land DEM is also from USGS

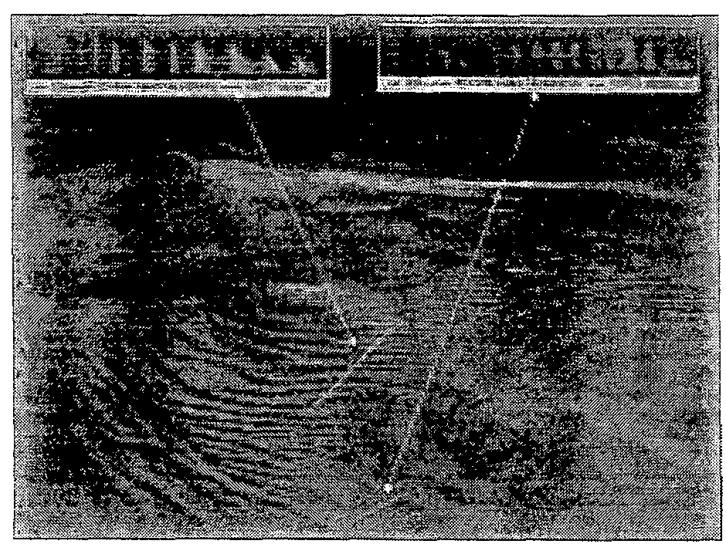

Fig. 3. Zoom in of image above showing 2 scales of bedforms, large sand waves of $2 \mathrm{~m}$ amplitude and small ripple $10-20 \mathrm{~cm}$ in amplitude. Also visible are very small ( $5 \mathrm{~cm}$ amplitude), track parallel artifacts due to imperfect refraction correction.

Color, while used to represent depth in the images above can also be mapped to other parameters (like backscatter or sediment properties) and draped over the digital terrain model (Fig. 4). The user can interactively "fly" around the data and view it from all angles through the use of a 6-degree of freedom mouse that transforms simple hand motions into a data exploration tool (and thus the derivation of the name of software package - Fledermaus.). With special LCD glasses, the scene can be viewed in true stereo. Data entry is simple and 3-D interaction can take place within a few minutes of the production of a DTM or sonar mosaic. Thus if these products are produced on board the vessel, 3-D interaction can be used for quality control, mission planning and in some cases mission execution.

Through the use of object-oriented software architecture, multiple, individual data sets with different levels of resolution can be easily combined, georeferenced, and displayed. Thus land-based DEM's with one level of resolution can be combined with multiple bathymetric data

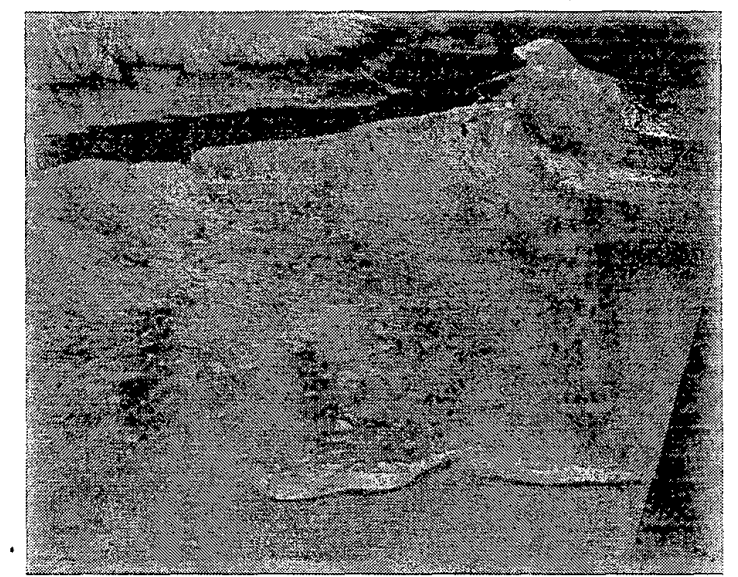

Fig. 4. $30 \mathrm{kHz}$ multibeam sonar-derived backscatter (high backscatter is light) data draped over $20 \mathrm{~m}$ pixel bathymetry off Oahu, Hawaii. Data provided by USGS. Land based $30 \mathrm{~m}$ DEM from USGS. Circular high-backscatter features are dumpsites from dredging of Pearl Harbor. Water depths range from 30 to $600 \mathrm{~m}$

with different levels of resolution without the need to regrid at a common scale (Figs 2, 4). Even more intriguing is the ability to texture map data at any level of resolution on top of lower resolution data. Thus high resolution backscatter or video imagery can be mapped directly on top of lower resolution bathymetry without the need to degrade the higher resolution data or waste memory by upsampling the lower resolution data (Fig 5.) 


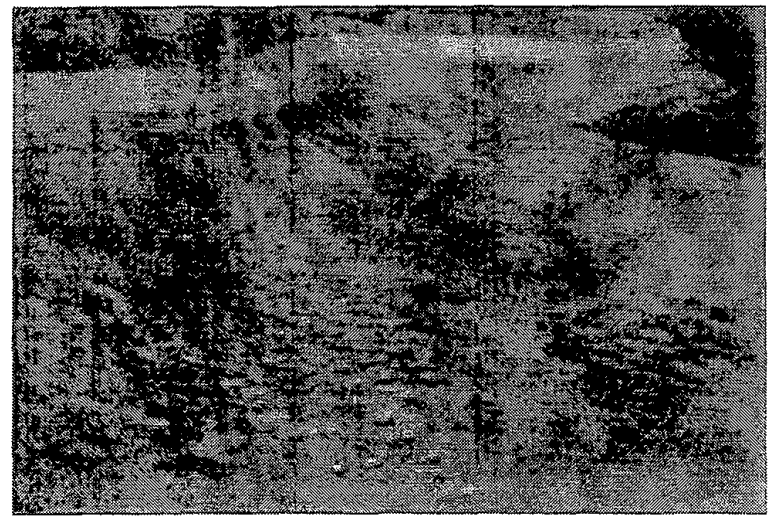

Fig. 5. High-resolution ( $5 \mathrm{~m}$ pixel) backscatter texture mapped on $20 \mathrm{~m}$ pixel resolution bathymetry data collected by USGS with $30 \mathrm{kHz}$ multibeam sonar off Oahu, Hawaii.

A series of analytical tools is also available that provides for the calculation of gradients, slopes, areas, volumes and differences, all in the 3-D environment.

\section{APPLICATIONS}

The combination of multiple, georeferenced data sets in a fully quantitative and interrogatable environment opens up a world of possibilities in terms of data analysis, environmental and engineering applications.

\section{A. Environmental Applications:}

The ability to drape or texture map backscatter or video imagery data on top of topographic data provides a powerful tool for studying the fate of offshore dumpsites. While many dumpsites are not directly discernable in bathymetric data (as was the case for those off Oahu (Figs. 4 and 5), they most often have a clear and pronounced backscatter signature. By draping backscatter over bathymetry, the distribution, area or volume of dumped material can be quickly calculated. As backscatter data becomes more quantitative, it can be analyzed to understand the nature and history of the dumped materials [2]. Derived sediment characterization parameters may be draped on top of bathymetry so as to better understand the distribution of seafloor types (and thus processes) with respect to seafloor morphology [2]. Additionally, the ability to clearly define bedforms and flow patterns (Figs. 2 and 3 ) becomes an important component of studies of the fate of offshore contaminants.

\section{B. Geological Applications:}

The interactive exploration of seafloor morphology and backscatter data in a 3-D environment is an extremely useful tool for understanding geologic processes. We cite two examples where the complete coverage and visualization capabilities offered by dense multibeam data have provided new insights that would have been difficult to discern from low density data sets. The first is from a survey conducted off Atlantic City, N.J., where the rendering in 3-D of 95 $\mathrm{kHz}$ multibeam sonar revealed a remarkable array of massive iceberg scours which had gone undiscovered in previous single beam surveys (Fig. 6).

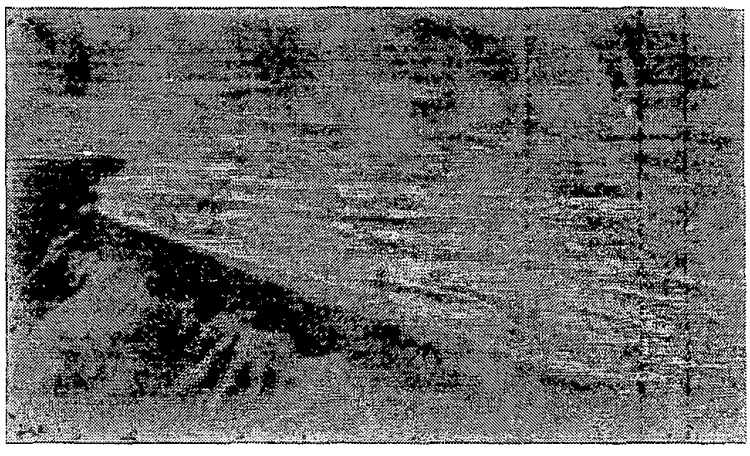

Fig. 6. Color-coded 3-D rendering of large iceberg scours off Atlantic City, N.J. Large scours are $20 \mathrm{~m}$ deep and $100 \mathrm{~m}$ across. Head of Tom's Canyon is on left - shelf break is at about $150 \mathrm{~m}$. Image represents about $30 \mathrm{~km}$ distance in foreground.

The second example is from a series of multibeam surveys conducted in Passamaquoddy Bay between Maine and New Brunswick. Here a $95 \mathrm{kHz}$ multibeam sonar revealed a huge concentration of pock marks. The ability to render these data in 3-D and to combine the bathymetry with aerial photography and geologic maps revealed that the pockmarks are lineated along the regional fault direction and that they are probably related to gas release associated with neotectonic activity (Fig.7). Numerous other examples of insights gained from the combination of dense data and 3-D visualization can be found in previously published studies $[3],[4],[5]$.

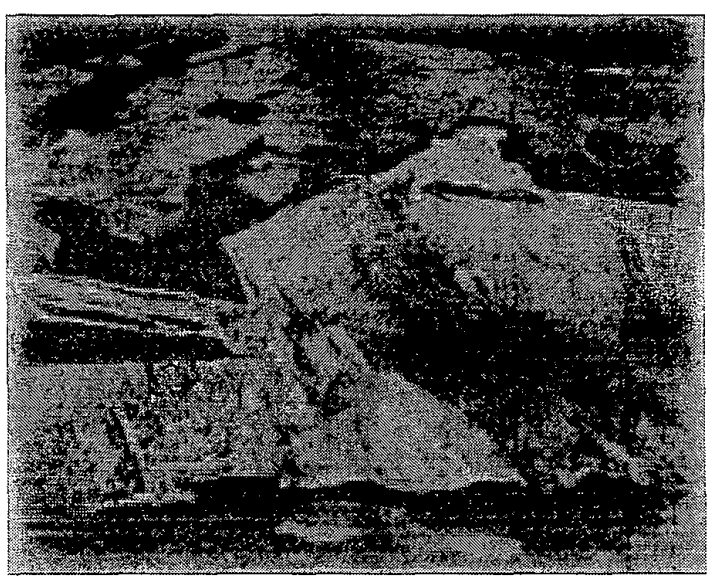

Fig. 7. $95 \mathrm{kHz}$ color-coded multibeam bathymetry from Passamaquoddy Bay, N.B. georeferenced with aerial photographs. Pockmarks (largest almost $100 \mathrm{~m}$ in diameter) form in lineations along well know structural (fault) trends. Multibeam bathymetry courtesy of Canadian Hydrographic Service. Aerial photos courtesy of Service N.B.

\section{Cable and Pipeline Route Planning Applications}

The planning and deployment of submarine cables and pipelines involve a massive investment of resources as well 
as huge risks. Fiber-optic cables are now typically plowed into the seafloor in waters to $1500 \mathrm{~m}$ presenting severe demands for a detailed understanding of seafloor slopes and material types. Pipeline planners have other constraints, with concerns about slopes, spans and substrate stability, all of which also require a detailed understanding of the nature of the seafloor on the prospective route.

The interactive 3-D environment provides a means for the cable and pipeline route planner to integrate the various data sets collected in support of the deployment (e.g., bathymetry, backscatter, video, and even seismic data) into an intuitive and easily interpretable form (Fig 8). A series of specialized tools has been developed to facilitate interactive cable and pipeline route planning including the export of profiles, gradients, cross-sections, turning points and other files used in the planning process [6].

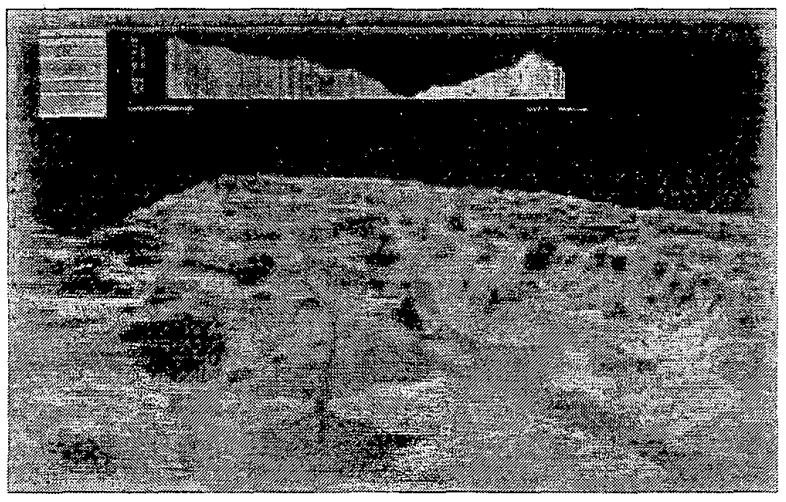

Fig. 8. Acoustic backscatter (yellow=high=rocks, blue=low $=$ sand and silt) draped on $95 \mathrm{kHz}$ multibeam bathymetry used for planning route of Sable Island gas pipeline. Data courtesy of Mobil Oil Co.

\section{Fisheries Applications}

The growing awareness of the need to understand and map critical fisheries habitats brings acknowledgement of the role that multibeam sonars and multiparameter 3-D mapping can play. Again the ability to superimpose and integrate multiple data sets in an intuitive and quantitative fashion allows complex inter-relationships to be discerned. In Fig. 9 we show color-coded backscatter (related to seafloor type) draped on multibeam bathymetry. Super-imposed on these data are color-coded trawl catch results (scaled to the positional uncertainty of the trawl). Presentation of these multiple variables in this manner allows the fisheries scientist to quickly understand the inter-relationships amongst seafloor morphology, seafloor material type and fish abundance.

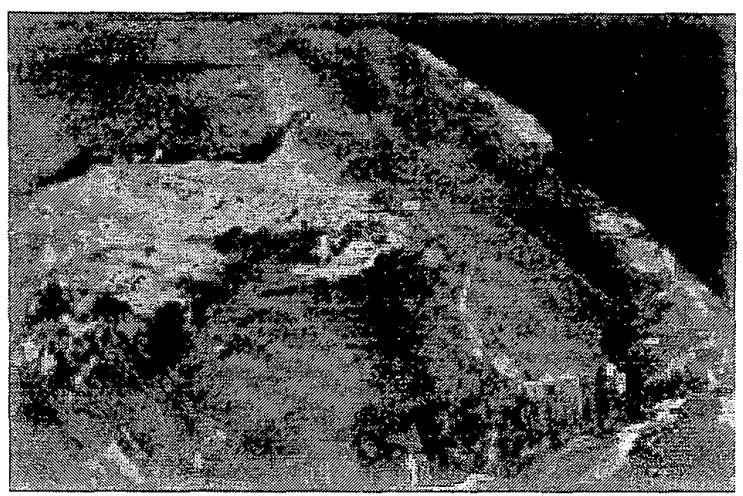

Fig. 9. Multibeam sonar backscatter data draped on bathymetry off Santa Monica Calif. Yellow is high backscatter. Santa Monica sewer pipe and diffuser is visible in upper part of image (y-shaped feature). Red-brown dots represent color-coded fish abundance as determined from trawl data. Multibeam data from USGS; trawl data from NMFS. From [7]. 
In addition to the use of multibeam sonar for mapping seafloor fisheries habitat we have also been exploring the use of multibeam sonar for the in situ mapping of fish and other targets in the water column (Fig 10). In this application a specially designed (to preserve midwater data) multibeam sonar has been used to map schools of fish several hundred meters to either side of the vessel. While individual fish are rarely mapped, the behavior of aggregations of fish can be studied, providing insight into schooling behavior and the important question of whether or not fish schools are actively avoiding survey vessels (and thus biasing hydroacoustic or trawl-based measurements of fish abundance). Future efforts will attempt to calibrate these systems in order to provide a direct measurement of biomass and perhaps even species identification [8], [9].

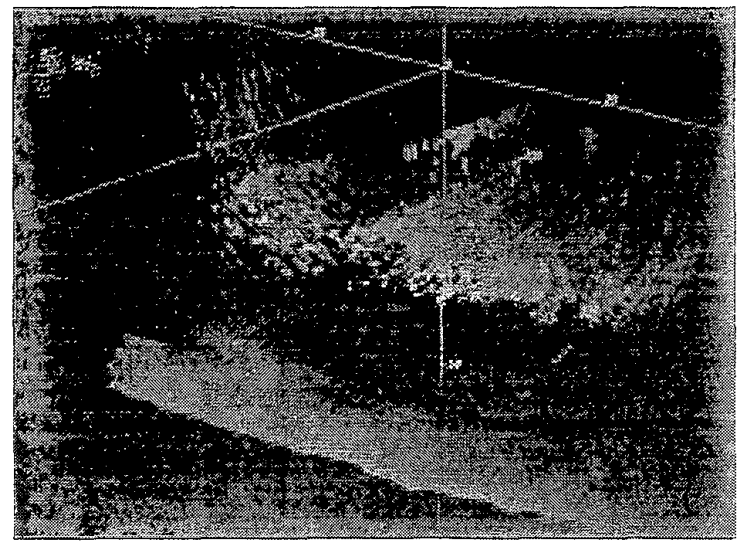

Fig. 10. 3-D visualization of seafloor (red) and herring school (green) collected with $200 \mathrm{kHz}$ multibeam sonar. Water depth is $50 \mathrm{~m}$.

\section{E. Data Fusion and Na vigation}

Many of the examples of applications already presented have demonstrated the power of the interactive 3-D environment for fusing multiple data sets. In this final example we explore applications for use of this environment as an aid in navigating both surface and deeply deployed (either ROV's or AUV's) vessels as well as a means to begin to integrate a much larger range of data types. In Fig. 11 we have brought together orthophotos, navigational charts and multibeam bathymetry from Sydney Harbor Australia. The combination of these data sets in a quantitative georeferenced 3-D environment provides the navigator with much more detailed information about the operational area than a standard chart. At the same time the navigator can be presented a full 3-D perspective of the position of his vessel with respect to either historical data or, as real-time underkeel clearance systems are developed, with respect to the actual determination of underkeel clearance (Fig. 12).

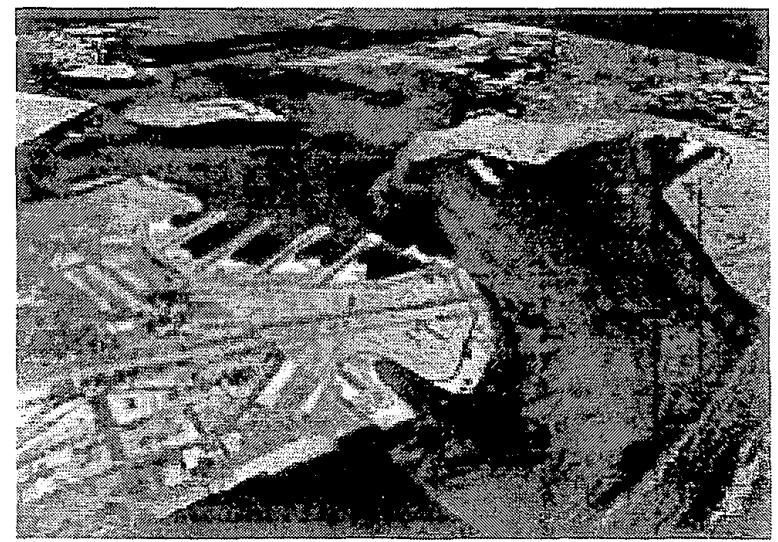

Fig. 11. Integration of an orthophoto, nautical chart and multibeam data from Sydney Harbour, Australia. Feature on bottom right of figure is excavation and backfill for the Sydney Harbor tunnel.

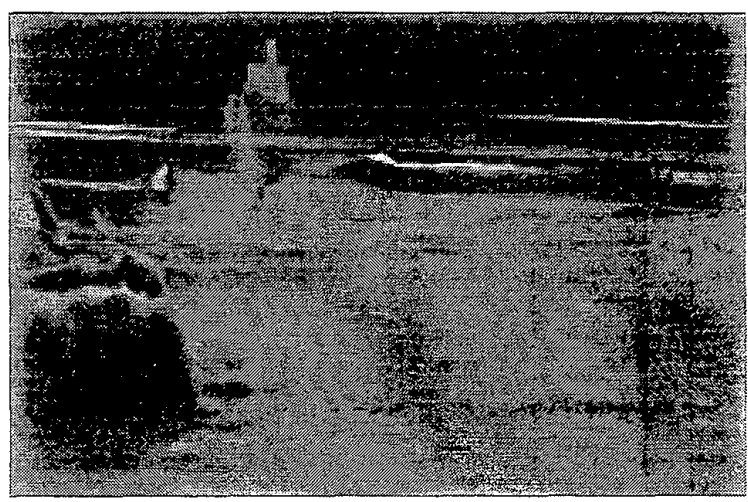

Fig 12. Perspective view of vessel moving through Sydney Harbor multibeam data set. In this case multibeam data is historical. Future applications will involve real-time determination of underkeel clearance and update of dataset.

Finally, we are in the process of developing a new 3-D environment that is designed to allow for the real-time visualization of ROV or AUV data in the context of 3-D bathymetry. This environment will enable us to integrate and fuse 3-D positioning information together with real-time and historic data from multiple vehicle-mounted sensors including sonars, physical and biological oceanographic measuring devices and video imagery (Fig. 13). 


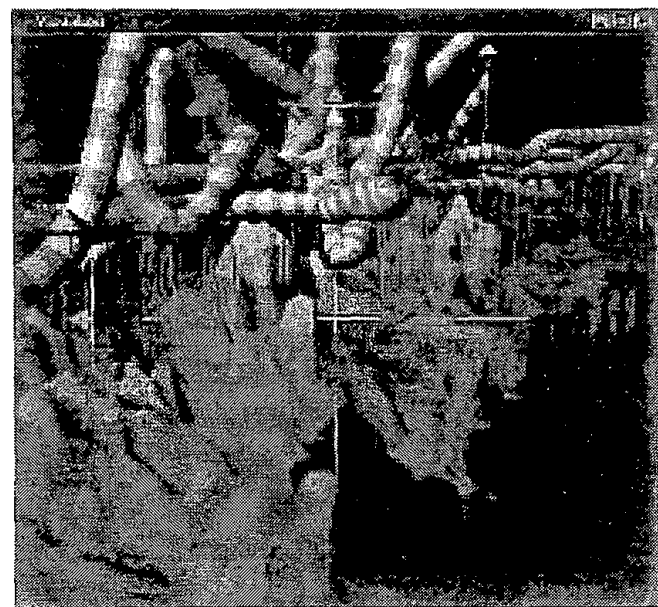

Fig. 13. ROV -track (tube) combined with sector-scanning sonar derived bathymetry and fish-count data (arrows) from survey of Endeavor segment of Juan de Fuca Ridge.

\section{CONCLUSIONS}

The past few years have seen dramatic advances in our ability to map the seafloor that have resulted from the convergence of advances in sonar technology, positioning capabilities and computer processing power. These new techniques produce massive data sets that can challenge our ability to process and manage the data. The great density of these data, however, offers the opportunity to take advantage of interactive 3-D visualization techniques that can provide an unprecedented perspective of seafloor morphology and processes.

The interactive 3-D environment can be fully quantitative, allowing the integration of multiple data sets each at its inherent level of resolution. Through color mapping, draping, texture mapping, and sun-illumination, multiple parameter data sets can be combined in a manner that allows for simple interpretation and numerous applications to geological, environmental, engineering and fisheries problems. Quantitative tools for data interrogation, measuring profiles, areas, volumes, differences, slopes and gradients provide a range of analytical possibilities and make these tools particularly suitable for cable and pipeline route planning.

The future will see the development of even more sophisticated sonar and positioning systems. With the inevitable advances in computer processing power that will be coincident with these other developments we are sure to see the continued development of 3-D visualization tools that will make our task of understanding the seafloor and ocean processes easier and easier.

\section{ACKNOWLEDGMENTS}

The authors gratefully acknowledge the support of NOAA Grant NA970G0241, ONR Grant N00014-95-1-0064, and NSERC support for the Chair in Ocean Mapping and CRD Grant 222653.

\section{REFERENCES}

[1] V. Renard and J.-P. Allenou, "SeaBeam, multibeam echo sounding in Jean Charcot; description, evaluation, and first results", Int. Hydrographic Rev., vol. 56, 1979 pp. 35-67

[2] L.A. Mayer, S. Dijkstra, J.E. Hughes Clarke, M. Paton, .and C. Ware, "Interactive tools for the exploration and analysis of multibeam and other seafloor acoustic data, in Pace, N.G., Pouliquen, E., Bergem., O., and Lyons., eds., High Frequency Acoustics in Shallow Water, SACLANT Conference Proceedings Series, CP-45, NATO SACTLANT Research Centre, La Spezia, Italy, 1997, pp. $355-362$

[3] J.V. Gardner, L.A. Mayer, and J.E. Hughes Clarke, "Morphology and processes in Lake Tahoe (California Nevada)", Bull. Geol. Soc. America, v 112, no. 5, ,. 2000 , p. $736-746$

[4] J.V. Gardner, L.A. Mayer, and J.E Hughes Clarke and A. Kleiner, "High-resolution multibeam bathymetry of East Flower Gardens and Stetson Bank, Gulf of Mexico", Gulf of Mexico Science, v. 16, no 2., 1998, p. $131-144$

[5] J. Goff, D.L. Orange, L.A. Mayer, and J.E, Hughes Clarke, "Detailed investigation of contintnetal shelf morphology from a high-resolution swath sonar survey over the Eel River Basin, Northern California", Marine Geology, v. 154, 1999, p. $255-270$

[6] M. Paton, L.A. Mayer, and C. Ware, "Interactive 3-D tools for pipeline route planning, Proceedings of the IEEEOceans 97, Vol. 2, C., 1997, pg. $1216-1222$

[7] J.V. Marinez Diaz, "Analysis of multibeam sonar data for the characterization of seafloor habitats, M.Sc. Thesis, Univ. of New Brunswick, 1999, 138 pp.

[8] L.A. Mayer, Y., Li, G. Melvin, and C. Ware, C., "The application of 3-D visualization technology to pelagic fisheries assessment and research", ICES, CM 1998/S:14, 1998 12pp.

[9] G. Melvin, Y., Li, L.A., Mayer, and A. Clay, "The development of an automated sounder/sonar acoustic logging system for deployment on commercial fishing vessels.", ICES CM 1998/S:14, 1998,16 pp 